\title{
15-dB Differential Link-Loss UDWDM-PON with Direct Beat Phase Modulated DFBs
}

\author{
J. Camilo Velásquez, Student Member, IEEE, Iván N. Cano, Victor Polo, Marc Domingo and Josep \\ Prat, Member, IEEE
}

\begin{abstract}
A 15 dB differential link-loss ultra-dense wavelength division multiplexing passive optical network (UDWDM-PON) with two optical network units (ONU) spectrally spaced $6.25 \mathrm{GHz}$ is experimentally implemented and tested. The ONU transmitters consist of direct phase modulated distributed feedback lasers (DFB) through a digital beat signal, whose amplitude and duty cycle are optimized for maximum phase variations, avoiding the need for an analogue equalizer. We achieved receiver sensitivities of $\mathbf{- 5 3} \mathrm{dBm},-\mathbf{5 0 . 5} \mathrm{dBm}$, and $\mathbf{- 4 5}$ $\mathrm{dBm}$ for bit rates of $1.25 \mathrm{~Gb} / \mathrm{s}, 2.5 \mathrm{~Gb} / \mathrm{s}$, and $5 \mathrm{~Gb} / \mathrm{s}$ respectively at $B E R=4 \cdot 10^{-3}$ with an intradyne coherent receiver.
\end{abstract}

Index Terms-Beat phase modulation, coherent detection, DFB, directly modulated laser (DML), UDWDM-PON.

\section{INTRODUCTION}

$\mathrm{I}^{\mathrm{N}}$ $\mathrm{N}$ recent years the development of commercial coherent transceivers has increased the capacity of long haul links. Its interest towards access networks in ultra-dense wavelength spacing has thus revamped. However, for this technology to be commercially attractive in access networks, the terminal units should be simple and as a result, cost-effective [1]. Furthermore, as the bandwidth (BW) requirements are different for each user, the transmitter (Tx) and receiver ( $\mathrm{Rx})$ should preferably adapt to the demanded bitrate $(\mathrm{Rb})$.

The most popular Tx in passive optical networks (PON) is a directly modulated laser (DML) due to its simplicity and lower cost as compared to external modulation [2]. Traditionally the output power of the DML is varied with the data signal producing an intensity modulation (IM) with high chirp broadening. Recently, a DML with phase modulation (PM) was proposed as Tx for UDWDM-PON [3]. In order to obtain a PM, a derivative analogue pre-equalizer based on a simple passive network was used. It related the inherent frequency modulation caused by the laser chirp to a PM. Though, the passive network had to be adapted when the $\mathrm{Rb}$ was modified to avoid performance penalties.

This work was supported in part by the Spanish Ministry of Science and Innovation FLIPER project TEC2015-70835-R and by the AGAUR under grant 2016FI_B 00758.

J. Camilo Velásquez, Victor Polo, Marc Domingo and Josep Prat are with the Department of Signal Theory and Communications, Universitat Politècnica de Catalunya, Barcelona 08034, Spain (e-mail: juavelasquez@tsc.upc.edu; polo@tsc.upc.edu; marc.domingo.ribe@ @alu-etstb.upc.edu; jprat@ tsc.upc.edu).

Iván N. Cano is now with Huawei Technologies ERC, München 80992, Germany (e-mail: ivan.cano@tsc.upc.edu).
In [4] we presented a DML driven by a digital beat signal to produce an optical PM, with no need for an analogue equalizer. The modulating data had three levels, and its amplitude and duty cycle (d-c) were adjusted.

In this work, we detail the setting of the beat signal parameters for several $\mathrm{Rb}$, add the sensitivity penalty when they are not optimized and furthermore find out the minimum channel spacing (CS) for several differential link-losses in the PON. We carry out tests at $1.25 \mathrm{~Gb} / \mathrm{s}, 2.5 \mathrm{~Gb} / \mathrm{s}$, and $5 \mathrm{~Gb} / \mathrm{s}$ achieving $\mathrm{Rx}$ sensitivities of $-53 \mathrm{dBm},-50.5 \mathrm{dBm}$ and -45 $\mathrm{dBm}$ respectively for a target forward error correction (FEC) of $\mathrm{BER}=4.10^{-3}[5]$. With this simple direct phase modulated Tx a CS of $6.25 \mathrm{GHz}$ and a differential link-loss of $15 \mathrm{~dB}$ is obtained at $2.5 \mathrm{~Gb} / \mathrm{s}$.

\section{EXPERIMENTAL SETUP}

The PON setup with two users is depicted in Fig. 1. The two $\mathrm{Tx}$ and $\mathrm{Rx}$ can operate in either upstream or downstream. $\mathrm{Tx}_{1}$ consisted of a directly modulated distributed feedback laser (DFB) which had $4 \mathrm{MHz}$ linewidth, $10 \mathrm{GHz}$ modulation bandwidth and emitted at $\lambda_{1}=1544.9 \mathrm{~nm}$. Data was a $2^{15}-1$ pseudo random binary sequence (PRBS) differentially encoded and digitally equalized by means of a 1-tap finite impulse response (FIR) filter. The result was a three level signal whose duty cycle was adjusted digitally. The data signal was uploaded into an arbitrary waveform generator (AWG) and the output power was varied by means of an $8 \mathrm{GHz}$ electrical amplifier (SHF98P). The DFB was biased at $75 \mathrm{~mA}$ in the regime where transient chirp is reduced. The electrical waveform directly modulated the DFB producing both an IM and a proportional adiabatic chirp [6]. The latter shifted the phase of the optical signal and was controlled by adjusting the amplitude and d-c [7]. As a result, an optical differential phase shift keying (DPSK) signal was generated. $\mathrm{Tx}_{2}$ was identical to $\mathrm{Tx}_{1}$ with a $3 \mathrm{MHz}$ linewidth, $2.5 \mathrm{GHz}$ modulation bandwidth DFB at $\lambda_{2}=1544.95 \mathrm{~nm}$. Thus, the spectral separation between users was set to $6.25 \mathrm{GHz}$. Data was also a PRBS $2^{15}-1$ with a different seed to keep it uncorrelated with respect to $\mathrm{Tx}_{1}$ data and with equal launched power of $0 \mathrm{dBm}$. Then they were combined in an optical $3 \mathrm{~dB}$ coupler and sent through $25 \mathrm{~km}$ of single mode fiber (SMF). Afterwards, a variable optical attenuator (VOA) emulated the coupling losses and limited the power into the Rx.

The Rx was based on intradyne detection with a 3x3 optical 

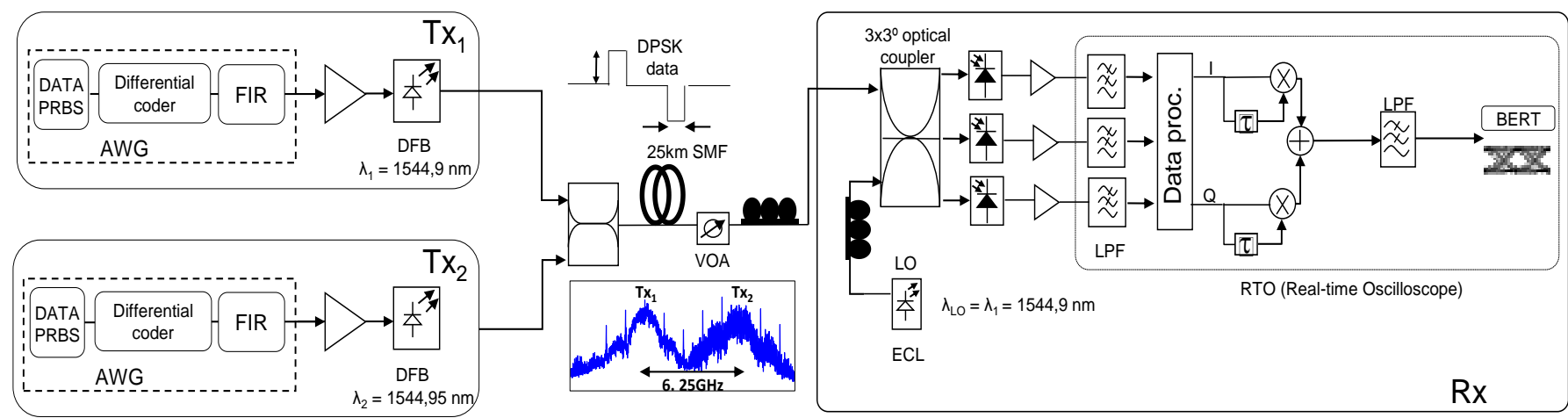

Fig. 1. Experimental schematics setup. The insets show the transmitted spectrum for both users $\mathrm{Tx}_{1}$ and $\mathrm{Tx}_{2}$ at $\mathrm{Rb}=1.25 \mathrm{~Gb} / \mathrm{s}$ and spaced $6.25 \mathrm{GHz}$.

coupler which mixed the optical signal with a local oscillator (LO). The LO was a $100 \mathrm{kHz}$ linewidth external cavity laser (ECL) with $0 \mathrm{dBm}$ optical power emitting at $\lambda_{\mathrm{LO}}=\lambda_{1}=1544.9$ $\mathrm{nm}$. The three outputs of the optical coupler were detected with $10 \mathrm{GHz}$ p-i-n- photodiodes (PDs) followed by low-noise electrical amplifiers. The electrical signals were low-pass filtered at $\mathrm{Rb}$, sampled and processed with a $50 \mathrm{GSa} / \mathrm{s}$ realtime oscilloscope. Then it were combined to obtain the inphase (I) and quadrature (Q) components as described in [8]. Each of the I and Q components were differentially demodulated and then added. Afterwards, the samples passed through a 4th order low-pass filter at cutoff frequency of $\mathrm{Rb}$ and the BER was computed. The Rx can be implemented in real-time with digital processing as demonstrated in [9].

\section{RESULTS}

When directly modulating a laser, there is an intrinsic frequency modulation (FM) produced by the laser chirp. The laser FM is related to a PM by an integral term. The instant phase of a DML can be written as [10]:

$$
\varphi(t)=2 \pi \int \Delta f(t) d t=\frac{\alpha}{2}\left(\ln P(t)+\int \kappa P(t) d t\right)
$$

where $P(t)$ is the signal power, $\alpha$ is the laser enhancement factor and $\kappa$ is the adiabatic chirp coefficient. At mid frequencies, the second term of (1), i.e. the adiabatic chirp, dominates. From (1) we observe that the phase depends on both the power and the time period of the signal.

To study this relation, we varied the amplitude and duty cycle of the modulating signal and measured the phase shift produced by the directly modulated DFB in optical back to back (btb). The results are plotted in Fig. 2a and Fig. $2 b$ for Rb $=1.25 \mathrm{~Gb} / \mathrm{s}$ and $2.5 \mathrm{~Gb} / \mathrm{s}$ respectively. The Rx measured the phase received from the computed $\mathrm{I}$ and $\mathrm{Q}$ components (constellations in the insets of Fig. 2) of $2^{15}$ bits. The same measurement was performed with $\mathrm{Rb}$ of $5 \mathrm{~Gb} / \mathrm{s}$ obtaining comparable results. The level lines in Fig. 2 were normalized to $\pi$ radians phase. We observe inside the $0.8 \cdot \pi$ area the required amplitude and duty cycle values to get a maximum phase shift.

The reason for using $0.8 \cdot \pi$ rad as boundary was derived from Fig. 3. The BER curves for different phase shifts were (a)
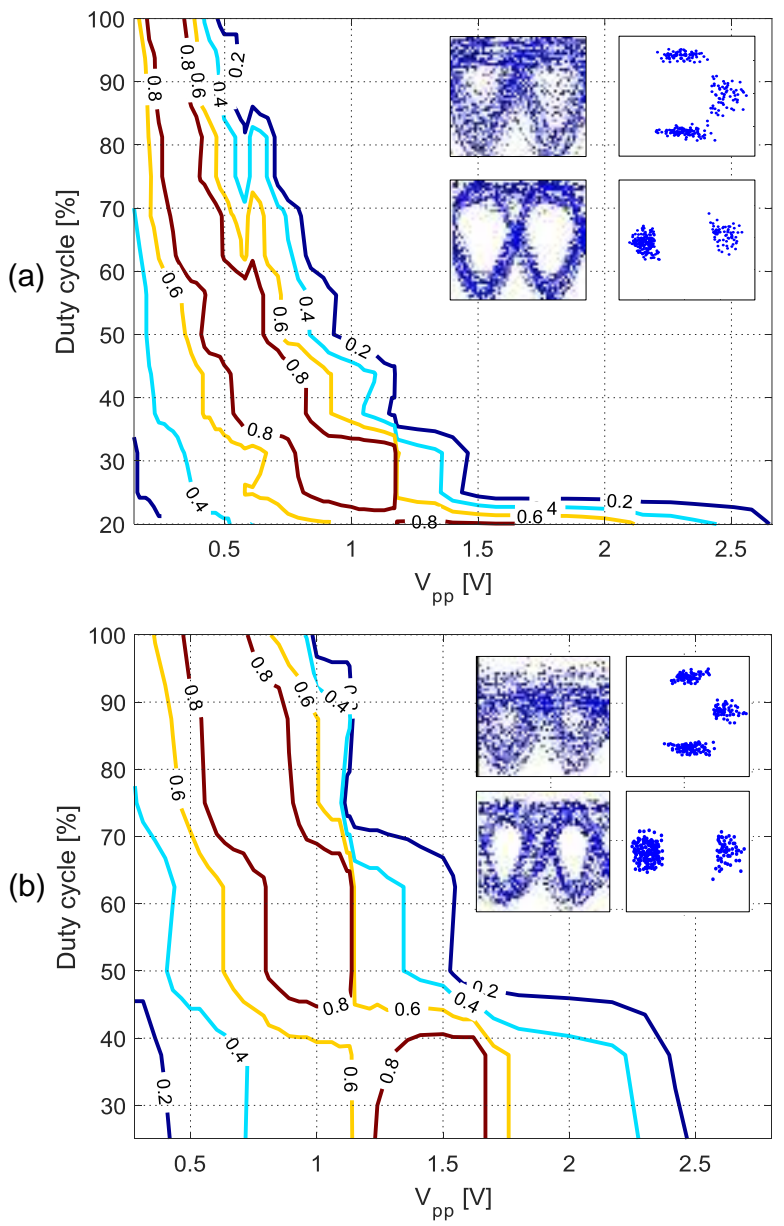

Fig. 2. Experimental phase shift obtained when changing the signal amplitude and duty cycle at (a) $\mathrm{Rb}=1.25 \mathrm{~Gb} / \mathrm{s}$ and (b) $\mathrm{Rb}=2.5 \mathrm{~Gb} / \mathrm{s}$. The level lines indicate the phase shift as proportion to $\pi$ radians, i.e. 1 represents $\pi$ radians. The insets shows the I \& $\mathrm{Q}$ and Eye diagrams for a phase shift of $\pi / 2$ (top) and $\pi$ (bottom) radians. The constellations show \pm phase shifts and for that reason the complex conjugate also appears.

evaluated for $\mathrm{Rb}$ of $1.25 \mathrm{~Gb} / \mathrm{s}, 2.5 \mathrm{~Gb} / \mathrm{s}$, and $5 \mathrm{~Gb} / \mathrm{s}$. The beat signal had $50 \% \mathrm{~d}-\mathrm{c}$ and corresponding peak-to-peak voltages of $0.5 \mathrm{~V}, 0.9 \mathrm{~V}$ and $1.6 \mathrm{~V}$ respectively. We took as a reference $\mathrm{BER}=10^{-4}$ and measured the required $\mathrm{Rx}$ power to achieve it. Then, the penalty was computed with respect to the lowest Rx power. Fig. 3 summarizes the penalty for the three $\mathrm{Rb}$. As observed, to keep the penalty $<1 \mathrm{~dB}$, the phase shift should be between $0.8 \cdot \pi$ to $1.2 \cdot \pi$. 


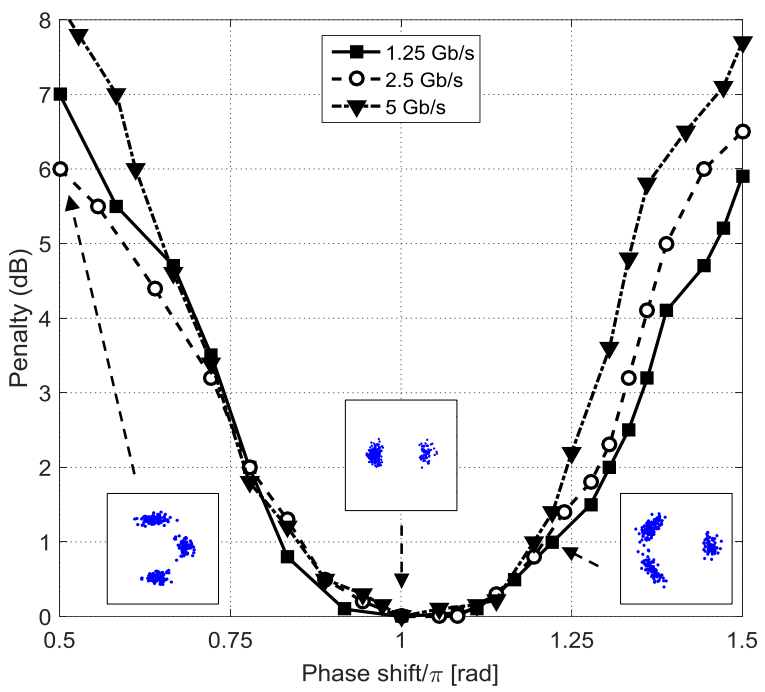

Fig. 3. Sensitivity penalty at BER of $10^{-4}$ against phase shift from $\pi$ rad. The $\mathrm{X}$-axes has been normalized to $\pi$ radians, i.e. 1 represents $\pi$ radians. The insets show the I \& $\mathrm{Q}$ diagrams of $\pi / 2 \mathrm{rad}, \pi \mathrm{rad}$ and $11 \pi / 9 \mathrm{rad}$. The constellations show \pm phase shifts and for that reason the complex conjugate also appears.

Fig. 4 shows the Rx sensitivity at $\mathrm{BER}=4 \cdot 10^{-3}$ against the duty cycle for $\mathrm{Rb}=1.25 \mathrm{~Gb} / \mathrm{s}, 2.5 \mathrm{~Gb} / \mathrm{s}$, and $5 \mathrm{~Gb} / \mathrm{s}$. We observe that for $\mathrm{Rb}=1.25 \mathrm{~Gb} / \mathrm{s}$ the penalty is negligible $(<1$ $\mathrm{dB}$ ) for all duty cycles. On the other hand, for $\mathrm{Rb}=2.5 \mathrm{~Gb} / \mathrm{s}$ and $5 \mathrm{~Gb} / \mathrm{s}$, the penalty increases to almost $2 \mathrm{~dB}$ and $1.5 \mathrm{~dB}$ respectively for duty cycles $>50 \%$. The reason for this penalty is mainly the higher residual IM. Also, it should be noted that the transmitted signal BW was more confined at $100 \%$ duty cycle compared with $50 \%$. For $5 \mathrm{~Gb} / \mathrm{s}$, we could not measure at $25 \%$ duty cycle because of limitation in the AWG resolution. Another remark from Fig. 4 is that the amplitude could be fixed (i.e. $0.9 \mathrm{Vpp}$, as indicated by red dotted diamonds) for a simpler and fully-digital reconfiguration of the d.c, according to the bitrate. This is especially of interest since normally the electrical amplifiers are not variable. Then, only the d-c has to be adapted in the Tx accordingly to maximize the performance when changing the $\mathrm{Rb}$.

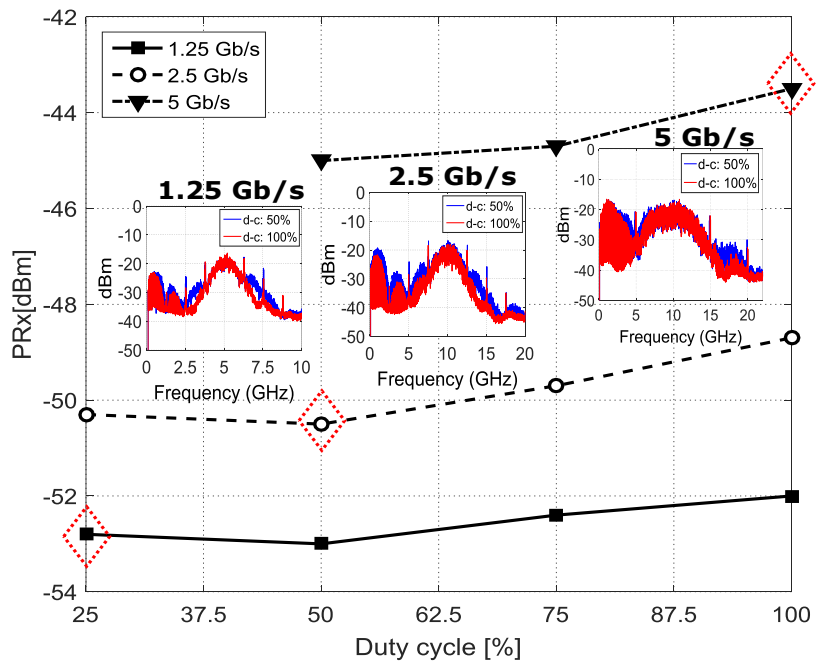

Fig. 4. Rx optical power against duty cycle (d-c) for beat phase modulated signals. The insets show the signal spectrum at $50 \%$ and $100 \% \mathrm{~d}-\mathrm{c}$ at relative intermediate frequency (IF) of $5 \mathrm{GHz}$ for $\mathrm{Rb}$ of $1.25 \mathrm{~Gb} / \mathrm{s}$ and at $\mathrm{IF}=10 \mathrm{GHz}$ for $2.5 \mathrm{~Gb} / \mathrm{s}$ and $5 \mathrm{~Gb} / \mathrm{s}$ The red dotted diamond indicate the performance when amplitude is left constant at different bit rates.
Then, we evaluate the sensitivity performance of the PON by measuring the BER of $\mathrm{Tx}_{1}$ in btb and with $25 \mathrm{~km}$ of SMF, with the beat signal having a d-c of $50 \%$. The results are plotted in Fig. 5. In optical btb the Rx sensitivities for a target $\mathrm{BER}=4 \cdot 10^{-3}$ are approximately $-53 \mathrm{dBm},-50.5 \mathrm{dBm}$ and -45 $\mathrm{dBm}$ at $\mathrm{Rb}$ of $1.25 \mathrm{~Gb} / \mathrm{s}, 2.5 \mathrm{~Gb} / \mathrm{s}$ and $5 \mathrm{~Gb} / \mathrm{s}$ respectively. Penalties below $0.5 \mathrm{~dB}$ are obtained when $25 \mathrm{~km}$ of SMF is added. The lower performance of the $5 \mathrm{~Gb} / \mathrm{s}$ signal is mainly explained by the limited BW of the electrical amplifier.

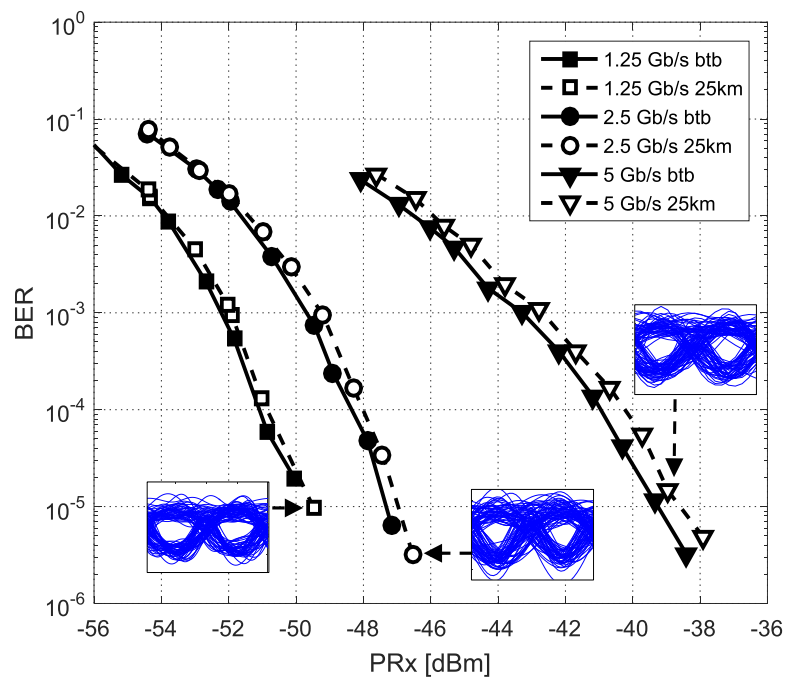

Fig. 5. BER against Rx optical power for $50 \%$ d-c beat phase modulated signals at $\mathrm{Rb}=1.25 \mathrm{~Gb} / \mathrm{s}, 2.5 \mathrm{~Gb} / \mathrm{s}$ and $5 \mathrm{~Gb} / \mathrm{s}$. The insets show the eye diagrams for BER $=10^{-5}$ at the three bit rates evaluated.

We also evaluated the minimum spectral separation between users at $1.25 \mathrm{~Gb} / \mathrm{s}$ and $2.5 \mathrm{~Gb} / \mathrm{s}$. $\mathrm{Tx}_{2}$ was modulated identically to $\mathrm{Tx}_{1}$ and $\lambda_{2}$ was tuned in temperature to get shiftsteps of $1.25 \mathrm{GHz}$. The Rx optical power was left constant at the value where $\mathrm{BER} \approx 10^{-4}$. Then, the performance of $\mathrm{Tx}_{1}$ was evaluated. In addition, the Tx power of the users was also varied to study its effect on the CS. The power difference between users was changed from $-15 \mathrm{~dB}$ to $15 \mathrm{~dB}$ following the differential link-loss specified in ITU-T 989.2 Recommendation [11].

Fig. $6 \mathrm{a}$ and $6 \mathrm{~b}$ show the BER against the $\mathrm{CS}$ for $\mathrm{Tx}_{1}$ at $\mathrm{Rb}$ of $1.25 \mathrm{~Gb} / \mathrm{s}$ and $2.5 \mathrm{~Gb} / \mathrm{s}$ respectively. At $\mathrm{Rb} 2.5 \mathrm{~Gb} / \mathrm{s}$, when both users $\left(\mathrm{Tx}_{1}\right.$ and $\left.\mathrm{Tx}_{2}\right)$ are emitting at the same optical power, $\mathrm{PTx}_{1}=\mathrm{PTx}_{2}$, the minimum CS to keep the penalty $\leq 1$ $\mathrm{dB}$ (quantified when passing from $\mathrm{BER}=10^{-4}$ to $\mathrm{BER}=7 \cdot 10^{-}$ ${ }^{4}$ ) is of $4.375 \mathrm{GHz}$. However, when the optical power of the $\mathrm{Tx}_{2}$ is $15 \mathrm{~dB}$ higher, the minimum CS increases to $6.25 \mathrm{GHz}$.

Fig. $6 \mathrm{c}$ depicts the required $\mathrm{CS}$ to keep penalty $\leq 1 \mathrm{~dB}$, at $1.25 \mathrm{~Gb} / \mathrm{s}$ and $2.5 \mathrm{~Gb} / \mathrm{s}$, with a differential link-loss from -15 $\mathrm{dB}$ to $15 \mathrm{~dB}$. It is interesting to observe that if a channel is being randomly tuned in the PON, its power should be reduced to $15 \mathrm{~dB}$ less than the neighbor channel to limit the penalty incurred. In fact, the penalty would be $<1 \mathrm{~dB}$ even when its spectrum is passing just over the other channel. In the limit of a differential link-loss of $15 \mathrm{~dB}$, the $6.25 \mathrm{GHz}$ spaced PON would still operate at $\mathrm{Rb}$ of $1.25 \mathrm{~Gb} / \mathrm{s}$ and $2.5 \mathrm{~Gb} / \mathrm{s}$ per user, as indicates the dotted lines in Fig 6c. In consequence, a $\mathrm{Tx}$ at $\mathrm{Rb}=1.25 \mathrm{~Gb} / \mathrm{s}$ or $2.5 \mathrm{~Gb} / \mathrm{s}$ could work in a $6.25 \mathrm{GHz}$ spaced PON with a differential link-loss of $15 \mathrm{~dB}$. 

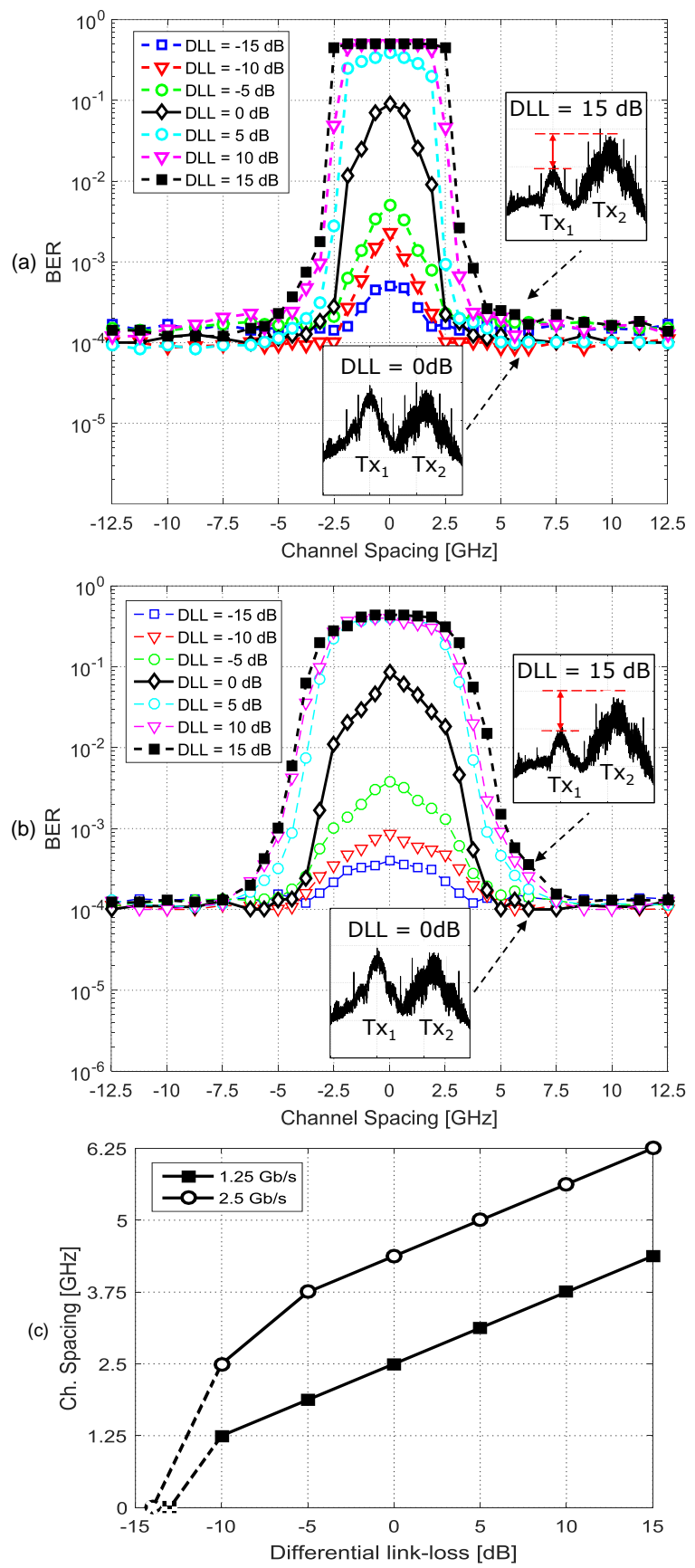

Fig. 6. BER vs CS for Tx1 at several differential link-losses (DLL) for (a) $1.25 \mathrm{~Gb} / \mathrm{s}$ and (b) $2.5 \mathrm{~Gb} / \mathrm{s}$. The insets show the electrical spectrum of two users spaced $6.25 \mathrm{GHz}$ with DLL of $0 \mathrm{~dB}$ and $15 \mathrm{~dB}$; (c) CS vs DLL for $1 \mathrm{~dB}$ sensitivity penalty at $\mathrm{BER}=10^{-4}$. The dotted lines indicate penalties $<1 \mathrm{~dB}$.

Finally, we compare our results with the PtP WDM PON approach (CS of $100 \mathrm{GHz})$ defined for NGPON2 (1603 nm$1625 \mathrm{~nm})$ [11] in terms of aggregate capacity. If the entire band were used, up to 27 users at $10 \mathrm{~Gb} / \mathrm{s}$ could be served with NGPON2 with an aggregate capacity of $270 \mathrm{~Gb} / \mathrm{s}$. With UDWDM-PON (CS of $6.25 \mathrm{GHz}$ ) the total number of users at $2.5 \mathrm{~Gb} / \mathrm{s}$ that could potentially be served is 440 and the aggregated capacity reaches $1.1 \mathrm{~Tb} / \mathrm{s}$ improving by a factor of 4 compared to PtP WDM option of NGPON2. However, the emitted power per channel must be reduced to $-6 \mathrm{dBm}$ for safeguarding the eye safety limit of $21.3 \mathrm{dBm}$ [1]. The link budget available would be $44.5 \mathrm{~dB}$ which would allow for the splitting losses (27 dB for 1:512) and $87.5 \mathrm{~km}$ reach $(\alpha=0.2$ $\mathrm{dB} / \mathrm{km}$ ) while keeping the performance above the FEC threshold. These results along with the low complexity of the transceivers potentially makes this technique an attractive option for flexible future optical access networks.

\section{CONCLUSION}

A direct phase modulation of a DFB laser with a digital beat signal is proposed and experimentally demonstrated in a coherent UWDM-PON at $1.25 \mathrm{~Gb} / \mathrm{s}, 2.5 \mathrm{~Gb} / \mathrm{s}$ and $5 \mathrm{~Gb} / \mathrm{s}$ in a $25 \mathrm{~km}$ SMF link, with Rx based on an intradyne detector. By digitally optimizing the d-c for each bitrate, the amplitude of the beat signal could be constant and an optical DPSK signal would be produced when directly modulating a DFB. The maximum tolerable phase shift to keep the performance penalty $<1 \mathrm{~dB}$ for all the bit rates, was around $0.8 \cdot \pi$ to $1.2 \pi$ radians. Rx sensitivities of $-53 \mathrm{dBm},-50.5 \mathrm{dBm}$ and $-45 \mathrm{dBm}$ were achieved at $1.25 \mathrm{~Gb} / \mathrm{s}, 2.5 \mathrm{~Gb} / \mathrm{s}$, and $5 \mathrm{~Gb} / \mathrm{s}$ respectively. Moreover, spectral separation as low as $6.25 \mathrm{GHz}$ between adjacent channels operating at $\mathrm{Rb}$ of $2.5 \mathrm{~GB} / \mathrm{s}$ is enough to keep the performance penalty $\leq 1 \mathrm{~dB}$ with a differential linkloss of $15 \mathrm{~dB}$. Even though this results show the technical feasibility for an UDWDM implementation, further analysis related with the cost are encouraged for future work.

\section{REFERENCES}

[1] J. Prat, I. Cano, M. Presi, I. Tomkos, D. Klonidis, G. Vall-llosera, R. Brenot, R. Pous, G. Papastergiou, A. Rafel and E. Ciaramella., "Technologies for Cost-Effective udWDM-PONs," J. Lightw. Technol., vol. 34, no. 2, pp. 783-791, Jan. 15, 2016.

[2] Y. Luo, H. Roberts, K. Grobe, M. Valvo, D. Nesset, K. Asaka, H. Rohde, J. Smith, J. Shan Wey and F. Effenberger., "Physical Layer Aspects of NG-PON2 Standards-Part 2: System Design and Technology Feasibility [Invited]," J. Opt. Commun. Netw., vol. 8, no. 1, pp. 43-52, Jan. 2016.

[3] I. Cano, A. Lerín, V. Polo and J. Prat, "Direct Phase Modulation DFBs for Cost-Effective ONU Transmitter in udWDM PONs," IEEE Photon. Technol. Lett., vol. 26, no. 10, pp. 973-975, May 15, 2014.

[4] J. C. Velásquez, I. N. Cano, V. Polo and J. Prat., "Direct Beat Phase Modulated DFB for flexible 1.25-5 Gb/s Coherent UDWDM-PONs," in Proc. OFC, Los Angeles, CA, USA, Mar 2017, pp. 1-3, paper ThA.32.

[5] T. Mizuochi., "Next Generation FEC for Optical Communication," in Proc. OFC, San Diego, CA, USA, Feb 2008, pp. 1-33, paper OTuE5.

[6] D. Mahgerefteh, Y. Matsui, X. Zheng, and K. McCallion, "Chirp Managed Laser and Applications," IEEE J. of Selected Topics in Quantum Electronics, vol. 16, no. 5, pp. 1126 - 1139, Sept/Oct., 2010.

[7] R. S. Vodhanel, "5 Gbit/s Direct Optical DPSK Modulation of a 1530nm DFB Laser,” IEEE Photon. Technol. Lett., vol 1, no. 8, pp. 218-220, August, 1989.

[8] C. Xie, P. J. Winzer, G. Raybon, A. H. Gnauck, B Zhu, T. Geisler and B. Edvold., "Colorless Coherent Receiver Using 3x3 Coupler Hybrids and Single-Ended Detection," Opt. Exp., vol 20, no.2, 1164-1171, Jan. 16, 2012.

[9] I. N. Cano, J. Prat, J. Tabares, J. C. Velásquez, S. Ghasemi, V. Polo, G. Y. Chu, M. Presi, E. Ciaramella, M. Rannello, F. Bottoni, M. Artiglia, G. Cossu, R. Pous, G. Azcárate, C. Vilà, H. Debrégeas, G. Vall-llosera, A. Rafel., "Field-Trial of Low-Cost Coherent UDWDM-PON with RealTime Processing, $\lambda$-Monitoring and EPON Coexistence," in Proc. ECOC, Düsseldorf, Germany, Sep 2016, pp. 1-3, paper M.1.E.5.

[10] D. Che, Q. Hu, F. Yuan, Q Yang, and W. Shieh., "Enabling Complex Modulation of Directly Modulated Signals Using Laser Frequency Chirp," IEEE Photon. Technol. Lett., vol 27, no. 22, pp. 2407-2410, Nov. 15, 2015.

[11] 40-Gigabit-capable Passive Optical Networks (NG-PON2): Physical media dependent (PMD) layer specification, ITU-T G.989.2 Recommendation, Dec. 2014. 